\title{
Influential Factors of Knowledge Sharing of Multinational E-Health Service Based on 24HrKF
}

\author{
Huosong Xia, Wuhan Textile University, Wuhan, China \\ Gan Xiong, Wuhan Academy of Educational Science, Wuhan, China \\ Juan Weng, Wuhan Textile University, Wuhan, China
}

\begin{abstract}
In order to solve the problem of cross-time and cross-regional medical collaboration and distributed knowledge sharing across patients and medical teams for 24 hours a day in the context of global resource allocation, a new $24 \mathrm{HrKF}$ e-health service model is proposed and a key knowledge model of $24 \mathrm{HrKF}$ e-health team knowledge sharing is established based on existing research results combined with $24 \mathrm{HrKF}$ distributed team characteristics. Finally, the questionnaire data of 338 multinational medical team members are used to verify the impact of key factors on the knowledge sharing of medical teams. The results shows that factors such as information and communication technology, the hospital's cultural characteristics, cross-cultural communication, medical knowledge and skills, and trust all have a significantly positive impact on knowledge sharing among team members especially information and communication technology and medical knowledge and skills. However, the degree of time-span separation across time zones has no significant effect on the knowledge sharing among team members.
\end{abstract}

\section{KEYWORDS}

24-Hour Knowledge Factory (24HrKF), E-Health, Global Operation, Knowledge Sharing

\section{INTRODUCTION}

With the rapid development of information technology, the scope of global information sharing has been continuously expanding. The medical data is increasing day by day, and there is growing focus on how such data can be used to measure and improve health care (Kumar, Vimala, \& Aravind Britto, 2019; Bates, Heitmueller, \& Saria, 2018). However, health care informatics is undergoing a revolution (Hassan, El Desouky, Elghamrawy, \& Sarhan, 2018). Even though the cost of health care continues to grow worldwide (Razmak, Bélanger, \& Farhan, 2018), but the potential for improving health and health care through bringing together multiple sources of data are great (Bates et al., 2018). E-health as a response to the voluminous data available in the health care sector, is driven and developed by the information technology generation, and has been applied in many aspects (Razmak et al., 2018). 
For example, "Zhuling" has been treated by medical experts around the world with the help of the Internet, "Ebola" and HIV have received great attention and been focused on prevention through social media (Chan \& Ghose, 2014), information technology links the world's excellent medical resources and supplements the insufficiency of regional medical level (Srivastava \& Shainesh, 2015). The establishment and popularization of System of Medical Reports increases medical efficiency (Dessì, Reforgiato Recupero, Fenu, \& Consoli, 2018). And there are many e-health applications such as mobile health, health on the internet, health information systems, clinical decision support systems and others (Leung \& Chen, 2019). Regardless of individual disease diagnosis, or medical information sharing, or efficiency of national medical resource allocation and global medical synergy, the e-health model can not only enhance the prevention and treatment of diseases, achieve good social benefits, but also bring huge economic benefits.

At present, e-health care is in the stage of development and promotion. Current researches on e-health are mainly focused on regional e-health cooperation (Bao, Ke, \&Wei, 2014; Tsuruya, Kawashima, Shiozuka, Nakanishi, \& Sugiyama, 2018), the use and promotion of medical information systems and electronic health file systems (Kuwabara, Yagahara, \& Ogasawara, 2018; Su, He, Guan, Jiang, \& Yang, 2017; Razmak et al., 2018), control of medical risks(Su et al., 2017) and personal medical information sharing (Lee, Lu, Yang, \& Chang, 2019). However, there is not only a lack of systematic thinking from the perspective of global resource allocation to study knowledge sharing among patients and medical teams in the context of globalization, asynchronization, cross-time and distributed, but also a lack of thinking from the perspective of all-day, cross-time and cross-cultural global medical collaboration among patients and medical teams in the context of globalization. And it is critical for real-world applicability to situate e-Health systems within the context-specific needs (Calvillo-Arbizu et al., 2019). Therefore, how to solve the problem of all-day, cross-time, cross-regional medical collaboration and distributed knowledge sharing among patients and medical teams under the background of global resource allocation? How to optimize the efficiency of e-health cooperation in the context of globalization?

It is found that Amar Gupta's global operation idea of "24-hour knowledge factory (24HrKF)" can better solve the problem of knowledge sharing across time zones and regions when establishing knowledge sharing and service model of transnational e-health care (Gupta, Seshasai, Mukherjo, \& Ridge, 2007). 24HrKF builds seamless sharing across time zones and making up for the shortcomings of asymmetry of time and space, promotes the collaboration and sharing of knowledge tasks, shortens the production process, reduces time and cost, and conversely transforms the time difference into the strategic advantage of the organization (Xia \& Li, 2016). Therefore, $24 \mathrm{HrKF}$ plays an irreplaceable role in modern medical field.

According to Cognitive resource diversity theory, diversity can be a valuable benefit to team performance through personal beliefs, ways of thinking, values, assumptions, and preferences (Chan, 2014; Mannix \& Neale, 2005). This theory proposes that functional diversity actually helps teams achieve higher levels of performance (Williams \& O'Reilly, 1998). Synergy theory holds that through synergy, organizational integration is not a simple sum of organizational elements, but through the active integration of people, so that the elements of the organizational system and subsystems can work together (Bi, Huang, \&Li, 2012). It focuses on how to realize the orderly structure of time and space through internal synergy without equilibrium or under non-equivalence conditions (Gao, 2018). Thus, throughout the paper we rely on the theoretical framework of Cognitive Resource Diversity Theory and Synergy Theory as a platform to address these important "how" questions: How to solve the problem of all-day, cross-time, cross-regional medical collaboration and distributed knowledge sharing among patients and medical teams under the background of global resource allocation? How to optimize the efficiency of e-health cooperation in the context of globalization?

In this regard, based on the collaborative innovation of multinational e-health, and combined with the $24 \mathrm{HrKF}$ operation mode, this paper reviews and summarizes the research results of $24 \mathrm{HrKF}$ allday operation, hospital knowledge sharing and the influencing factors of knowledge sharing among 
transnational electronic medical teams at home and abroad, and it attempts to explore the key factors and influencing mechanism of knowledge sharing among e-health teams based on 24HrKF from a more comprehensive perspective. The hypotheses based on knowledge sharing factors of $24 \mathrm{HrKF}$ transnational e-health care are gradually put forward by group discussion and theoretical induction, and the research model is determined. The data needed for the research are obtained by questionnaires among members of e-health with foreign medical project experience or overseas exchange experience, so as to validate the research model.

\section{LITERATURE REVIEW AND CONCEPTUAL MODEL}

\subsection{Literature Review}

\subsubsection{HrKF Global Operations Team}

The "24-Hour Knowledge Factory" is first proposed by Amar Gupta et al. It is a "knowledge-type factory" formed by three or more groups, subsidiaries or offices distributed in different time zones. The project teams use the time difference to coordinate the tasks in order to complete the same project. The sub-teams distributed in different time zones work according to the daytime working hours of the time zone, and complete the project through the continuous delivery of the task module to implement the project 24 hours a day uninterruptedly. The global operation of $24 \mathrm{HrKF}$ mainly starts from two aspects: the operating environment and task coordination. The operating environment mainly focuses on the application and innovation environment of 24HrKF (Hinojo-Lucena, Aznar-Díaz, CáceresReche, \& Romero-Rodríguez, 2018); The main task of collaborative research is task coordination and knowledge sharing. Collaborative social networks play a fundamental role in bringing people from different territories together in the same virtual space that it favors the exchange of information (Piening $\&$ Salge, 2016). 24HrKF is mainly based on asynchronous, distributed, and global knowledge (Gupta, Mattarelli, Seshasai, \& Broschak, 2009). Many international organizations participate in European projects about clinical care and health policy to achieve health goals that would be unattainable when operating solely within one's own country (Singer, Bakker, \& Redekop, 2019). Therefore, the 24HrKF-based globally distributed team has the following typical characteristics:

Firstly, there are cultural differences among different distributed teams, and each team must have the capability of cross-cultural communication. Ahmad found that the operating environment of multinational corporations (MNC) is multilingual, adding complexity to knowledge sharing among employees (Ahmad \& Barner-Rasmussen, 2019). In addition, team members in different regions cannot maintain communication at all times. According to Alsharo's research, trust positively influences virtual team collaboration (Alsharo \& Ramirez, 2016). Therefore, 24HrKF-based global collaboration also depends on trust among members (Ahmad \& Barner-Rasmussen, 2019). The impact of such differences on knowledge sharing among individuals in the MNC is particularly significant (Ahmad \& Barner-Rasmussen, 2019).

Secondly, the overlap and coupling of working time across time zones are required. In CSCW (computer-support cooperative work) environment, the coupling degree refers to the intensity and degree that information sharing and communication level which are required to complete the task (Olson \& Olson, 2000), that is, the nature of a dependency relationship among tasks, has an impact on the way to complete and organize sharing works. First of all, 24HrKF-based team members are distributed in different time zones, the working environment has very high coordination requirements. Secondly, in the $24 \mathrm{HrKF}$ mode, members should carry out the assigned independent task modules to minimize the need for communication. Therefore, team sub-tasks assigned by $24 \mathrm{HrKF}$ should be low-coupling, thus enabling team members to complete tasks independently.

Thirdly, cross-time zones, cross-cultural and distributed collaboration rely on the support of information and communication technology. The distributed teams rarely communicate face to face, so task coordination and team communication are inefficient (Tagliaventi \& Mattarelli, 2006). The 
global operation of $24 \mathrm{HrKF}$ must rely on a large number of technical collaborations and related institutional support to create a shared platform with various social media tools and realize quick and timely information communication and knowledge sharing.

\subsubsection{Knowledge Sharing of Hospital Electronic Medical Team}

Due to concentration of medical knowledge of patients and medical talents, hospitals are typical knowledge organizations. Study of hospital medical operation methods and knowledge sharing can play an important role in both disease treatment and hospital management (Zhang, 2006). With the arrival of the era of knowledge economy, knowledge sharing is crucial for attaining a competitive edge in organizations (Oyemomi, Liu, Neaga, Chen, \& Nakpodia, 2018). Therefore, the power of the entire medical system can be used to medical activities through medical knowledge sharing among organizations (Liu \& Lin, 2004).

With the rise of hospital medical information technology, Zhang (2006) divided the e-health knowledge sharing into explicit knowledge sharing (valuable historical data and pictures, medical innovation record and other knowledge) and invisible knowledge sharing (clinical practice, the common experience and lessons of dealing with problems).

\subsubsection{Influencing Factors of Knowledge Sharing of Multinational Electronic Medical Teams}

Because of the complexity of the health care system and the ever-changing demand for health care, effective and efficient collaboration within the team is needed. Therefore, knowledge sharing is essential for cross-professional health care teams (Ko"rner et al., 2016). By studying the internal influence mechanism of international strategic alliance, Sklavounos, Rotsios, and Hajidimitriou (2015) found that trust has a positive impact on effective knowledge transfer among partners in transnational alliance organizations. Jamshed and Majeed (2019) concluded that a conducive team culture provides a platform for sharing knowledge and knowledge sharing positively influences team performance of health-care teams.

The above studies have summarized the influence of different factors on knowledge sharing from the dimensions of organizational culture, geographical distribution, trust, and the external environment of the enterprise. However, the medical organization is different. For example, large public hospitals are non-profit and have medical service. These studies provide direction for us to study the knowledge sharing of multinational medical teams. Bordoloi and Islam (2012) proposed that knowledge absorption and application, occupational characteristics of doctors, disease characteristics, use of information technology, and organizational culture characteristics have influence on e-health task delivery and knowledge sharing among doctors. Gadd et al. (2011) proposed that information communication technology, trust, et al. have an impact on knowledge sharing behavior in the process of acceptance and use of e-health information technology. However, several applications for hospital management purposes appear to be not very widespread (Olivero et al., 2019). In addition, there is no research from the perspective of distributed cross-regional e-health team, and it is limited to the internal factors of hospitals.

From the perspective of transnational distributed medical cooperation, the provision of treatment through telemedicine has proved to be an effective way to obtain treatment opportunities (Lin, Casteel, Shigekawa, Weyrich, Roby, \& McMenamin, 2019). In addition, the use of information and communication technology plays a decisive role in hospital knowledge sharing and efficient service (Avanesova \& Shamliyan, 2019). The above studies have provided typical cases for regional e-health care, transnational e-health care, and e-health care service models, and have paved the way for multinational e-health team knowledge sharing research. However, the following deficiencies still exist: 
Firstly, although case studies on advanced multinational medical organizations have proposed many factors affecting the knowledge sharing among multinational e-health teams, few consider the impact of the cross-cultural communication of medical teams and the time difference on knowledge sharing among electronic medical teams. Both of these are key factors for knowledge sharing among multinational e-health teams and occupy an important position in the research of $24 \mathrm{HrKF}$.

Secondly, the existing researches have proposed the possible impacts of various key factors from the perspective of globalization and electronic operation by case studies. However, few cases validate the factors provided by questionnaires of medical team members.

Based on the above researches on knowledge sharing among transnational operation teams of enterprises and e-health teams, we summarize the key factors affecting knowledge sharing capability as shown in Table 1. In response to the above issues, we combine the $24 \mathrm{HrKF}$ idea with the typical characteristics of the global distributed electronic medical team, and further analyze the factors affecting medical knowledge sharing under the global 24HRKF operation mode based on the survey data of multinational medical teams.

\subsection{Conceptual Model}

The past two decades have seen much development in health Information Communication Technology (ICT) relating to electronic Personal Health Record (ePHR) systems. And ePHR systems are developed to support the delivery and management of nursing pathways throughout the health system (Irizarry, Dabbs, \& Curran, 2015). With the changing global economic environment, technological trends and user needs, the key to successful knowledge sharing is the ability to acquire appropriate knowledge at the right time and place, so that the members of a team can complete his or her work more efficiently (Ambos \& Ambos, 2007). And it requires us to study how the use of information and communication technology in e-medical teams affects knowledge sharing at the individual and team levels.

Secondly, according to 24HrKF's characteristics of cross-time zone, cross-region, and worktime coupling, 24HrKF-based electronic medical team will be composed of dispersed teams in different regions. Previous researches have not specifically analyzed how the separation of work hours differences affects knowledge sharing, so it is important to better understand how time isolation affects knowledge sharing.

Thirdly, according to the cross-cultural characteristics of $24 \mathrm{HrKF}$, the three factors of the hospital's cultural characteristics, cross-cultural communication skills and medical knowledge and skills should also be taken into consideration. Previous researches only proposed the possible impact of the three factors by cases research. Therefore, combined with the characteristics of the multinational electronic medical team and previous researches, it can be inferred that hospital cultural characteristics, crosscultural communication skills, and medical knowledge and skills will also affect the knowledge sharing behavior of multinational e-health team members.

Finally, good internal trust is also conducive to the knowledge sharing of multinational corporations (Bell \& Zaheer, 2007); B. Ambos and T. Ambos's (2009) studies about cross-regional and cross-cultural also proved that geographical dispersion and cultural differences can affect the effectiveness of knowledge transfer.

Therefore, on the basis of summarizing the researches on the characteristics of dimensions of multinational distributed teams and knowledge sharing based on the $24 \mathrm{HrKF}$ global operating model, we have considered this issue from six parts (information and communication technologies, the separation of time zones, hospital culture characteristics, cross-cultural communication skills, medical knowledge skills and trust) based on the characteristics of distributed teams of $24 \mathrm{HrKF}$ to explore the factors affecting knowledge sharing of e-health teams in the context of globalization. According to the above six parts, this study builds a model based on the key factors of $24 \mathrm{HrKF}$ transnational electronic medical teams, as shown in Figure 1. Next, we will analyze the hypotheses further. 
Table 1. Summary of Key Factors

\begin{tabular}{|c|c|c|c|}
\hline Author & $\begin{array}{l}\text { Research } \\
\text { Object }\end{array}$ & $\begin{array}{l}\text { Key Influencing Factors of } \\
\text { Knowledge Sharing Research }\end{array}$ & Progress and Insufficiency \\
\hline $\begin{array}{l}\text { Gupta\& Govindarajan } \\
\text { (1991) }\end{array}$ & Corporate & $\begin{array}{l}\text { Structural characteristics, task } \\
\text { environment, behavior requirements }\end{array}$ & \multirow{6}{*}{$\begin{array}{l}\text { Summarized the impact of } \\
\text { different factors on knowledge } \\
\text { sharing, but did not analyze the } \\
\text { knowledge sharing among team } \\
\text { members from the perspective } \\
\text { of the operation of hospitals } \\
\text { and medical teams. }\end{array}$} \\
\hline Bordoloi and Islam (2012) & Corporate & Organization culture & \\
\hline Piening \& Salge (2016) & Corporate & Geographic distribution & \\
\hline Jamshed \& Majeed (2019) & Corporate & $\begin{array}{l}\text { Enterprise organization structure, } \\
\text { external environment, trust } \\
\text { mechanism, corporate culture }\end{array}$ & \\
\hline Dawes \& Gharawi (2018) & Corporate & $\begin{array}{l}\text { Organizational motivation, absorptive } \\
\text { capacity, organizational capacity }\end{array}$ & \\
\hline Shaw \& Luiz (2017) & Corporate & Organizational distance & \\
\hline Bordoloi \& Islam (2012) & Hospital & $\begin{array}{l}\text { Knowledge absorption and application, } \\
\text { physician occupational characteristics, } \\
\text { disease characteristics, Information } \\
\text { technology use, organizational culture } \\
\text { characteristics }\end{array}$ & \multirow{6}{*}{$\begin{array}{l}\text { The impact of different factors } \\
\text { in the e-health environment was } \\
\text { verified, but it was limited to } \\
\text { internal factors in the hospital. } \\
\text { This study lacks consideration } \\
\text { from the perspective of a } \\
\text { distributed e-health team. }\end{array}$} \\
\hline Zelmer et al. (2017) & Hospital & Information technology & \\
\hline Scott et al. (2018) & Hospital & Information technology & \\
\hline Tallman \& Chacar (2011) & Hospital & Information technology & \\
\hline $\begin{array}{l}\text { Marlow, Lacerenza, } \\
\text { Paoletti, Burke, \& Salas } \\
\text { (2018) }\end{array}$ & Hospital & Trust, Team Communication & \\
\hline Gadd et al. (2011) & Hospital & $\begin{array}{l}\text { Perceived ease of use, perceived } \\
\text { usefulness, information } \\
\text { communication technology, trust }\end{array}$ & \\
\hline $\begin{array}{l}\text { Al-Ansari \& Alshare } \\
(2019)\end{array}$ & Hospital & $\begin{array}{l}\text { Information and communication } \\
\text { technology (ICT) }\end{array}$ & \multirow{4}{*}{$\begin{array}{l}\text { Many factors affecting } \\
\text { the knowledge sharing of } \\
\text { multinational electronic } \\
\text { medical teams were proposed. } \\
\text { However, the cross-cultural } \\
\text { communication between } \\
\text { medical teams and the time } \\
\text { difference between different } \\
\text { countries were not considered. } \\
\text { The key factors were put } \\
\text { forward through case analysis, } \\
\text { and sample data validation was } \\
\text { lacking. }\end{array}$} \\
\hline $\begin{array}{l}\text { Wickramasinghe, } \\
\text { Chalasani, Goldberg, \& } \\
\text { Koritala (2012) }\end{array}$ & Hospital & Information technology & \\
\hline $\begin{array}{l}\text { Dessì, Reforgiato } \\
\text { Recupero, Fenu, \& } \\
\text { Consoli (2018) }\end{array}$ & Hospital & $\begin{array}{l}\text { Team network partnership, team } \\
\text { network trust, information and } \\
\text { communication technology use, } \\
\text { medical expertise }\end{array}$ & \\
\hline $\begin{array}{l}\text { Bates, Heitmueller \& } \\
\text { Saria (2018) }\end{array}$ & Hospital & $\begin{array}{l}\text { Distance, information and } \\
\text { communication technology, medical } \\
\text { team cooperation }\end{array}$ & \\
\hline
\end{tabular}

\section{RESEARCH HYPOTHESIS}

\subsection{Impact of Use of ICT on Knowledge Sharing}

Significant progress has been made in information and communication technology (ICT) in the 21 st century. Adopting new ICT in organizations has become indispensable (Al-Ansari \& Alshare, 2019). ICT has great potential to improve the quality and efficiency of health care services (Nisha, Iqbal, \& Rifat, 2019). Previous studies have shown that there are huge transnational differences in the availability and use of ICT in the field of medical services (Zelmer et al., 2017). The level of computer 


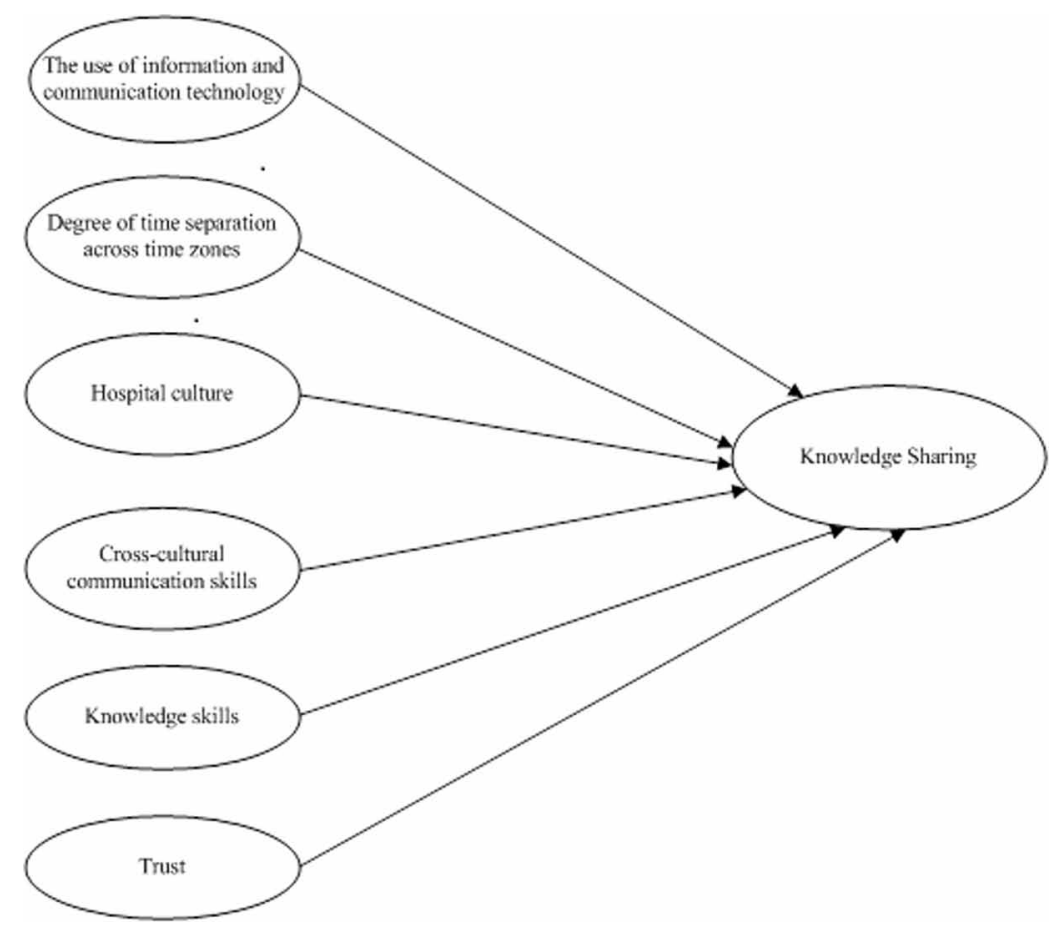

skills of medical workers and patients is one of the most important obstacles in the implementation of telemedicine (Scott et al., 2018). Using ICTs facilitates knowledge sharing among knowledge workers with barriers of time zone and space, and improves the accessibility of information.

The use of information and communication technology is a powerful way to promote knowledge sharing and knowledge management from the perspective of individual interactions (Mitchell, 2003), communication technology based on information technology is a common and useful tool for companies to seek competitive advantage on a global scale. In a globally distributed team across time zones, time zone differences make it difficult to achieve synchronous communication and realtime interaction among members in discussing tasks. Therefore, team managers are more willing to assign and communicate tasks and share knowledge through related technical support (Griffith \& Neale, 2003). Therefore, we propose the hypothesis:

H1: For 24HrKF-based e-health team, the higher the application level of ICT, the better it is to improve the team's knowledge sharing capability.

\subsection{Impact of Time Separation on Knowledge Sharing}

For time-zone separated team members, because of the need to choose between asynchronous communication and synchronous communication when their working hours are overlapping, the interaction among teams are affected by the degree of time separation. The study confirms that the time difference among members presents a positive correlation with their coordinated delays, and this effect is even more severe when there is no overlap of working time among them (Cummings \& Pickering, 2009). So, the timing for interaction is also particularly important. Based on these findings, we make the hypothesis: 
H2: The greater the degree of time separation among 24HrKF-based electronic medical team members, the weaker the team's knowledge sharing capabilities.

\subsection{The Influence of Hospital Cultural Characteristics on Knowledge Sharing}

Staadt (2015) found that organizational culture is the most prominent enabler in enhancing knowledge sharing in transnational projects. There is a certain cultural distance among different medical teams. It will inevitably lead to some differences among the employees of different teams in their understanding and behavioral norms, thus affecting the capability of team knowledge sharing. Davenport and Prusak (1998) proposed that the elements of corporate culture (such as values, norms, and behaviors) are decisive factors that influence the success of knowledge sharing. Different cultural backgrounds, goals and objectives can weak the enthusiasm of knowledge sharing and knowledge creation and consistency of purpose. Bordoloi and Islam (2012) proposed that knowledge sharing in medical service organizations depends on factors such as leadership and organizational culture. It can be seen that the cultural characteristics of hospitals based on $24 \mathrm{HrKF}$ across time zones, regions, and distributed electronic medical teams play an important role in knowledge sharing. Based on this, we propose hypothesis for knowledge sharing activities:

H3: The more open and innovative the cultural characteristics of the hospital where members of the $24 \mathrm{HrKF}-$ based e-health team are, the more conducive to improving the knowledge sharing capability.

\subsection{The Influence of Cross-Cultural Communication Skills on Knowledge Sharing}

Similarly, due to the heterogeneity of knowledge of e-health teams distributed in different regions and countries and differences in hospital cultural characteristics, 24HrKF-based e-health teams also need to conduct cross-cultural communication with internal or external staff based on differences in their social and cultural backgrounds. Team communication is consistently identified as a critical component of team performance (Marlow, Lacerenza, Paoletti, Burke, \& Salas, 2018). Culture is embedded in thinking and behavior. Even after they manage to receive the intended message, that is, the knowledge meant to be shared, they doubt the trustworthiness of the knowledge because of the difficult communication process and the suspicion created during the process (Lauring \& Zhang, 2018). In this multinational cross-cultural team cooperation and communication, individual ability to work across different cultures and organizational absorptive capacity, or the ability to take advantage of new knowledge, contribute substantially to mitigating the influences of cultural and knowledge distances respectively (Dawes \& Gharawi, 2018). In the management of a cross-cultural and collaborative project, good cross-cultural communication capability and skills are the core factors for project management, and failure of project management is often the failure of communication (Wang, 2004). Therefore, cross-cultural communication plays an important role in the cross-cultural knowledge sharing activities and team operations of the whole e-health team. We propose the hypothesis:

H4: For 24HrKF-based e-health teams, the stronger the cross-cultural communication capability, the better the knowledge sharing capability.

\subsection{The Effect of Doctors' Knowledge and Skills on Knowledge Sharing}

When setting up a $24 \mathrm{HrKF}$ distributed medical team, we should also consider that team members need different medical skills and can be responsible for different aspects of specific tasks, and maximize knowledge sharing capability on the premise of ensuring the successful completion of tasks. In the process of global operation, the knowledge of team members is diversified, and it has a certain impact on the sharing of information among team members. Sutcliffe (2002) found that the diversity 
of individual functions in the team can facilitate the sharing of information, and Jehn and Neale (1999) and Wang and Peng (2012) found that differences in knowledge and skills of team members can promote knowledge sharing among team members. Therefore, doctors' medical knowledge and skills can promote knowledge sharing among team members across time zones across time zones. Therefore, we propose the hypothesis:

H5: For 24HrKF-based e-health team members, the richer the knowledge and skills they have, the more beneficial it is to enhance the knowledge sharing capabilities.

\subsection{The Impact of Trust on Knowledge Sharing}

For 24HrKF-based electronic medical teams, building up trust in general among globally distributed team members is crucial (Trainer \& Redmiles, 2018), and factors related to people in distributed team members such as interpersonal trust and interpersonal connections are considered to be important contributors to knowledge sharing (Schiuma, Franssila, Okkonen, Savolainen, \& Talja, 2012). From the perspective of trust commitment theory, Hashim found that trust and commitment mediate relations and exchanges by establishing a cooperative environment between the parties concerned (Hashim \& Tan, 2015). Trust allows for nuances and tacit knowledge to be amplified and transferred (Shaw \& Luiz, 2017). That is, when a member believes that he or his team members are reliable and capable of supporting him, he will be more satisfied with the upcoming flow of knowledge. Based on the above discussion, this study makes the following hypothesis:

H6: For 24HrKF-based e-health team members, the stronger the mutual trust among members, the more beneficial it is to enhance knowledge sharing capabilities.

\section{RESEARCH METHODS}

\subsection{Scale Design and Data Collection}

\subsubsection{Scale Design}

In order to validate the model, seven potential variables, i.e. the degree of information and communication technology use, the degree of time separation across time zones, hospital cultural characteristics, cross-cultural communication capability, knowledge skills, trust and knowledge sharing capability, have been measured in Figure 1. All variables are measured by Likert scale 5, 1 (strongly disagreed) to 5 (strongly agreed). According to the scale designed by previous studies, the degree of information and communication technology use is developed in combination with the hospital characteristics in the study, including four measurement indicators. Variables of time separation degree across time zones are measured by direct reference to Espinosa and Carmel (2003), the hospital cultural characteristics scale has been revised, including four measurement indicators. Based on previous studies, the cross-cultural communication competence scale for outsourced enterprises is developed with the characteristics of hospitals. It contains four measurement indicators. Knowledge skills, trust and knowledge sharing capability are measured directly by existing measurement indicators. The measurement items and source literature of the scale are shown in Table 2.

\subsubsection{Data Collection}

As the subjects of the survey need to meet the $24 \mathrm{HrKF}$ transnational operating conditions, the doctors or team members who have experiences of studying abroad, foreign exchanges, or foreign medical projects in the hospital are investigated. 
Table 2. Scale Design

\begin{tabular}{|c|c|c|}
\hline Variable & Measurement Item & References \\
\hline $\begin{array}{l}\text { Use of Information } \\
\text { and communication } \\
\text { technology (ICT) }\end{array}$ & $\begin{array}{l}\text { 1) The hospital has advanced computer and system software. } \\
\text { 2) Doctors in different departments communicate by computers, } \\
\text { which greatly improves work efficiency. 3) I can easily obtain } \\
\text { the information required for my job by computer software. 4) I } \\
\text { often use QQ, e-mail and other text communication software to } \\
\text { communicate with colleagues. }\end{array}$ & $\begin{array}{l}\text { Learn from Al-Ansari } \\
\text { \& Alshare (2019) and } \\
\text { the characteristics of the } \\
\text { hospital to explore }\end{array}$ \\
\hline $\begin{array}{l}\text { Interval Time Zone } \\
\text { Separation (TZS) }\end{array}$ & $\begin{array}{l}\text { The degree of separation of hours of work among members due } \\
\text { to time zone differences in the medical team (hours):0-3, 3-6, } \\
6-9,>9\end{array}$ & $\begin{array}{l}\text { Espinosa \& Carmel } \\
\text { (2010) }\end{array}$ \\
\hline $\begin{array}{l}\text { Hospital Culture } \\
\text { Characteristics (HC) }\end{array}$ & $\begin{array}{l}\text { 1) There will be many group collaborations between different } \\
\text { departments. 2) We work together in teams to rationally treat } \\
\text { patients. 3) Better working conditions in the medical team } \\
\text { will promote the improvement of medical efficiency. 4) I have } \\
\text { sufficient knowledge and experience to rationally treat patients }\end{array}$ & $\begin{array}{l}\text { Learn from Jamshed } \\
\text { \& Majeed (2019) } \\
\text { and combine hospital } \\
\text { characteristics to correct }\end{array}$ \\
\hline $\begin{array}{l}\text { Cross-cultural } \\
\text { communication skills } \\
\text { (CC) }\end{array}$ & $\begin{array}{l}\text { 1) I agree with the culture of the cooperative hospital. 2) I can } \\
\text { accurately understand what doctors in foreign hospitals (or other } \\
\text { cooperative hospitals in China) say.3) When there is a conflict } \\
\text { between the medical team and the foreign hospital (or other } \\
\text { domestic cooperative hospital), the two parties can communicate } \\
\text { with each other very well and solve the problems. 4) I have no } \\
\text { prejudice against the culture of the cooperative hospital }\end{array}$ & $\begin{array}{l}\text { Draw on the ideas } \\
\text { of Xia \& Li (2016) } \\
\text { and combined with } \\
\text { the characteristics of } \\
\text { hospitals to explore }\end{array}$ \\
\hline $\begin{array}{l}\text { Knowledge and Skills } \\
\text { (KAS) }\end{array}$ & $\begin{array}{l}\text { 1) Each doctor in our team is responsible for different tasks. } \\
\text { 2) Each doctor in our team has certain aspects of specific } \\
\text { knowledge. 3) The medical expertise that our team members } \\
\text { have involves all directions in the field }\end{array}$ & $\begin{array}{l}\text { Scott et al. (2018); Wang } \\
\& \text { Peng (2012) }\end{array}$ \\
\hline Trust (TR) & $\begin{array}{l}\text { 1) I think that team members have confidence in each other. } \\
\text { 2) I can trust other members who work with me. 3) Our team } \\
\text { members are very friendly. 4) I think members can consider each } \\
\text { other's feelings and show concern. }\end{array}$ & $\begin{array}{l}\text { Marlow, Lacerenza, } \\
\text { Paoletti, Burke, \& Salas } \\
\text { (2018) }\end{array}$ \\
\hline $\begin{array}{l}\text { Knowledge Sharing } \\
\text { (KS) }\end{array}$ & $\begin{array}{l}\text { 1) I often share information and experience with colleagues, } \\
\text { other hospital doctors, etc. 2) I often hold formal or informal } \\
\text { meetings with colleagues and other hospital doctors. 3) I often } \\
\text { discuss various patient cases with colleagues and other hospital } \\
\text { doctors. }\end{array}$ & $\begin{array}{l}\text { Gupta, Seshasai, } \\
\text { Mukherjo, \& Ridge } \\
\text { (2007) }\end{array}$ \\
\hline
\end{tabular}

First, we send the designed questionnaire to the academic team where the researchers are located, solicit the opinions of the experts and researchers in the team on the questionnaire, and modify the content according to their proposals.

Secondly, the researchers carry out pre-survey in Huang Gang, Wuhan Huang Gang Hospital of Traditional Chinese Medicine in Wuhan (Level 3), Tong Ji Huangzhou Hospital (Level 2), Guang Zhou Military Region Army General Hospital Wuhan Hospital (Level 3), Tong Ji Hospital (Level 3) and other hospitals on a certain scale. The pre-research is conducted to test the designed questionnaire. At the same time, the pre-research conducts interviews with four senior professors with experiences in foreign medical projects in TongJi Hospital to understand the key influencing factors of transnational e-health and make changes of the indicators. A total of 151 questionnaires are collected for this pre-research, including 123 valid questionnaires and 29 invalid questionnaires. As the result of the pre-survey is good, they are directly incorporated into the final survey results.

Thirdly, the questionnaire is made into web page through the online research platform "www. sojump.com" to collect survey data. In the first stage, under the guidance of doctors with transnational medical cooperation experiences in TongJi and Army General Hospitals, questionnaires are sent out to 
colleagues or students with experience in studying abroad or projects; in the second stage, search for contact information of director-level physicians in major hospitals in the country on "Chaodao Online" (www.haodf.com), a well-known online medical platform in China, and send questionnaires to them; In the third stage, the "questionnaire star" paid sample service is used to recommend questionnaires to doctors with experience of transnational cooperation, and the quality of the questionnaires is controlled.

The questionnaire survey began in December 2013 and ended by the end of January 2014. In this survey, a total of 452 questionnaires were collected, 114 invalid questionnaires were screened, and 338 valid questionnaires were finally obtained, with an effective rate of $74.8 \%$. Table 3 shows the statistical information of the sample, and Table 4 shows the descriptive statistics of the variables and the correlation coefficient matrix.

\subsection{Data Analysis and Hypothesis Testing}

Our research uses SPSS 19.0 and AMOS 17.0 for data processing. The specific data analysis process is as follows: the reliability test is performed on the sample by SPSS 19.0, the confirmatory factor analysis (CFA) is performed on the measurement model of the structural equation model using AMOS 17.0, and the path analysis is performed on the structural model, thus testing the hypothesis proposed in the paper.

\subsubsection{Reliability Validity and Confirmatory Factors Analysis}

Firstly, SPSS 19.0 is used to analyze the reliability of 6 variables including information and communication technology and hospital cultural characteristics. The results show that the Cronbach $\alpha$ of each variable is greater than 0.6, indicating that the questionnaires have a good reliability. Secondly, the results of confirmatory factor analysis (CFA) with AMOS 17.0 shows that the standardized coefficients of all factors are greater than 0.5 , and all are significant at the level of $p<0.001$, indicating that the questionnaires meet the requirements of validity. Table 5 shows the test results of reliability and validity.

\subsubsection{Path Analysis}

This study uses AMOS 17.0 to construct structural equation model, which mainly tests the direct path coefficients from information and communication technology, time separation across time zones, hospital culture, cross-cultural communication, medical knowledge and skills, and trust to knowledge sharing. From Table 6, it can be seen that the path coefficient from information and communication technology to knowledge sharing is $0.774(\mathrm{t}=8.488, \mathrm{p}<0.001)$, and the path coefficient from time separation across time zones to knowledge sharing is $0.039(\mathrm{t}=0.833$, not significant $)$. The path coefficient from hospital culture to knowledge sharing is $0.583(\mathrm{t}=6.283, \mathrm{p}<0.001)$. The path coefficient from cross-cultural communication to knowledge sharing is $0.698(\mathrm{t}=7.759, \mathrm{p}<$ $0.001)$. The path coefficient from medical knowledge skills to knowledge sharing is $0.774(\mathrm{t}=7.708$, $\mathrm{p}<0.001)$, the impact of trust on knowledge sharing is $0.626(\mathrm{t}=7.313, \mathrm{p}<0.001)$. The direct path coefficients from information and communication technology, hospital culture, cross-cultural communication, medical knowledge skills and trust to knowledge sharing are significant, indicating that the hypothesis $\mathrm{H} 1, \mathrm{H} 3, \mathrm{H} 4, \mathrm{H} 5, \mathrm{H} 6$ proposed in this study are confirmed. However, the path coefficient from time separation across time zones to knowledge sharing is not significant, and the hypothesis $\mathrm{H} 2$ is not valid. The test results are shown in Table 7, and the conclusions of this chapter will further analyze the assumptions of validity and non-validity.

\section{EMPIRICAL RESULTS}

The research takes doctors or their team members who have worked abroad or have experience in foreign exchange or overseas medical projects as samples. Based on $24 \mathrm{HrKF}$ and distributed team characteristics, it explores how information and communication technologies, degree of separation 
Table 3. Basic Statistics of the Sample( $N=338)$

\begin{tabular}{|c|c|c|c|}
\hline Variable & Options & Quantity & Proportion (\%) \\
\hline \multirow{4}{*}{ Hospital type } & tertiary general hospital & 188 & 55.6 \\
\hline & tertiary speciality hospital & 50 & 14.8 \\
\hline & secondary General hospital & 93 & 27.5 \\
\hline & secondary specialist hospital & 7 & 2.1 \\
\hline \multirow{7}{*}{ Department } & surgical & 82 & 24.3 \\
\hline & Internal Medicine & 81 & 24.0 \\
\hline & Pediatrics & 48 & 14.2 \\
\hline & ENT & 25 & 7.4 \\
\hline & Gynecology & 58 & 17.2 \\
\hline & General & 14 & 4.1 \\
\hline & other & 30 & 8.9 \\
\hline \multirow{4}{*}{ Working years } & Less than 3 years & 66 & 19.5 \\
\hline & 3-10years & 177 & 52.4 \\
\hline & 11-20years & 87 & 25.7 \\
\hline & 20 years or more & 8 & 2.4 \\
\hline \multirow{2}{*}{ Gender } & $\operatorname{man}$ & 121 & 35.8 \\
\hline & woman & 217 & 64.2 \\
\hline \multirow{6}{*}{ Age } & Under 25 years old & 52 & 15.4 \\
\hline & 26-30 years old & 82 & 24.3 \\
\hline & 31-35 years old & 127 & 37.6 \\
\hline & $36-40$ years old & 53 & 15.7 \\
\hline & $41-50$ years old & 21 & 6.2 \\
\hline & 50 and over & 3 & 0.9 \\
\hline \multirow{4}{*}{ Education } & College and below & 61 & 18.1 \\
\hline & Undergraduate & 184 & 54.4 \\
\hline & master's degree & 84 & 24.9 \\
\hline & $\mathrm{PhD}$ & 9 & 2.7 \\
\hline \multirow{5}{*}{ Job title } & primary & 100 & 29.6 \\
\hline & intermediate & 132 & 39.1 \\
\hline & Deputy Senior & 83 & 24.6 \\
\hline & High grade & 6 & 1.8 \\
\hline & other & 17 & 5.0 \\
\hline \multirow{4}{*}{ Cross-time zone separation } & $0-3 h$ & 188 & 55.6 \\
\hline & $3-6 h$ & 5 & 1.5 \\
\hline & $6-9 \mathrm{~h}$ & 73 & 21.6 \\
\hline & $>9 \mathrm{~h}$ & 72 & 21.3 \\
\hline
\end{tabular}


Table 4. Descriptive Analysis and Correlation Coefficient Matrix

\begin{tabular}{|l|l|l|l|l|l|l|l|l|l|}
\hline \multicolumn{1}{|c|}{ variables } & \multicolumn{1}{|c|}{$\mathbf{1}$} & \multicolumn{1}{c|}{$\mathbf{2}$} & \multicolumn{1}{c|}{$\mathbf{3}$} & \multicolumn{1}{c|}{$\mathbf{4}$} & $\mathbf{5}$ & $\mathbf{6}$ & $\mathbf{7}$ & $\mathbf{8}$ & $\mathbf{9}$ \\
\hline gender & 1 & & & & & & & & \\
\hline age & $-.144^{* *}$ & 1 & & & & & & & \\
\hline education & $-.196^{* *}$ & $.464^{* *}$ & 1 & & & & & & \\
\hline Knowledge sharing & .041 & .019 & $.217^{* *}$ & 1 & & & & & \\
\hline $\begin{array}{l}\text { Cross-cultural } \\
\text { communication }\end{array}$ & .030 & $.108^{*}$ & $.125^{*}$ & $.529^{* *}$ & 1 & & & & \\
\hline Trust & .105 & $-.111^{*}$ & -.041 & $.481^{* *}$ & $.595^{* *}$ & 1 & & & \\
\hline Hospital culture & .066 & .022 & .033 & $.440^{* *}$ & $.593^{* *}$ & $.686^{* *}$ & 1 & & \\
\hline Knowledge skills & .031 & .030 & $.111^{*}$ & $.551^{* *}$ & $.544^{* *}$ & $.657^{* *}$ & $.608^{* *}$ & 1 \\
\hline $\begin{array}{l}\text { Information and } \\
\text { communication } \\
\text { technology }\end{array}$ & -.012 & .018 & $.213^{* *}$ & $.642^{* *}$ & $.531^{* *}$ & $.505^{* *}$ & $.509^{* *}$ & $.537^{* *}$ & 1 \\
\hline mean value & 1.64 & 2.76 & 3.11 & 4.12 & 4.12 & 4.24 & 4.29 & 4.16 & 4.13 \\
\hline standard deviation & 0.48 & 1.13 & 0.75 & 0.80 & 0.62 & 0.58 & 0.56 & 0.67 & 0.72 \\
\hline
\end{tabular}

Note: * indicates that the correlation coefficient is significant at the $p<0.05$ level, and ${ }^{* *}$ indicates that the correlation coefficient is significant at the $p<$ 0.01 level.

across time zones, hospital cultural characteristics, cross-cultural communication skills, medical knowledge and skills, trust and other factors have direct impact on knowledge sharing from the perspective of doctors' cognition and collaboration. Based on the existing researches and theoretical exploration, six research hypotheses are put forward. According to confirmatory factor analysis and path analysis results, five hypotheses are valid and one hypothesis is not valid. The following conclusions can be drawn.

Firstly, as our hypotheses, information and communication technology, hospital cultural characteristics, cross-cultural communication skills, medical knowledge and skills, and trust have significantly positive effects on knowledge sharing among team members, indicating that the hospital's comprehensive medical information technology infrastructure, strong cooperation culture and atmosphere in a multinational distributed medical team can promote formal or informal knowledge sharing among doctors. And doctor's ability to use information and communication technologies, cross-cultural communication skills, mutual trust among team members, and medical professional skills can also promote cross-regional team members to explore the latest patient records and share their medical experiences.

Secondly, although all of the above factors can have a positive impact on knowledge sharing, information and communication technologies and medical knowledge and skills have a greater impact. It can be seen that when setting up a 24HrKF-based global distributed medical operation team, first of all, it should attach importance to the information and communication technology infrastructure of hospitals, and ensure that the team members can achieve real-time communication and knowledge collaboration through information technology in a cross-regional and cross-time environment. Next, before the establishment of the $24 \mathrm{HrKF}$ distributed medical team, strict selection and training of medical team members are required to enable the team members to have certain cross-cultural communication skills, different medical skills, and to be responsible for specific tasks in different aspects. Under the premise of the task, maximize the efficiency of the team's operations. Finally, when setting up a $24 \mathrm{HrKF}$ distributed medical team, the hospital should create a good atmosphere of teamwork and an atmosphere of trust among team members to promote communication among team members. 
Table 5. Test of Reliability and Validity

\begin{tabular}{|c|c|c|c|}
\hline variables & Measure item & Normalization coefficient & Alpha $\alpha$ \\
\hline \multirow{4}{*}{ Information and Communication Technology (ICT) } & ICT1 & 0.74 & \multirow{4}{*}{0.77} \\
\hline & ICT2 & 0.76 & \\
\hline & ICT3 & 0.73 & \\
\hline & ICT4 & 0.53 & \\
\hline \multirow{4}{*}{ Hospital Culture Characteristics (HC) } & $\mathrm{HC} 1$ & 0.59 & \multirow{4}{*}{0.69} \\
\hline & $\mathrm{HC} 2$ & 0.72 & \\
\hline & $\mathrm{HC} 3$ & 0.56 & \\
\hline & $\mathrm{HC} 4$ & 0.55 & \\
\hline \multirow{4}{*}{ Cross-cultural Communication skills (CC) } & $\mathrm{CC} 1$ & 0.58 & \multirow{4}{*}{0.72} \\
\hline & $\mathrm{CC} 2$ & 0.57 & \\
\hline & $\mathrm{CC} 3$ & 0.74 & \\
\hline & $\mathrm{CC} 4$ & 0.63 & \\
\hline \multirow{3}{*}{ Knowledge and Skills (KAS) } & KAS1 & 0.57 & \multirow{3}{*}{0.65} \\
\hline & KAS2 & 0.69 & \\
\hline & KAS3 & 0.61 & \\
\hline \multirow{4}{*}{ Trust (TR) } & TR1 & 0.64 & \multirow{4}{*}{0.75} \\
\hline & TR2 & 0.66 & \\
\hline & TR3 & 0.69 & \\
\hline & TR4 & 0.62 & \\
\hline Knowledge Sharing Capability (KS) & KS1 & 0.73 & 0.79 \\
\hline
\end{tabular}

Table 6. Path Analysis

\begin{tabular}{|l|l|l|l|l|l|l|l|l|}
\hline \multicolumn{1}{|c|}{ Path } & $\begin{array}{c}\text { Path } \\
\text { coefficient }\end{array}$ & \multicolumn{1}{|c|}{ T value } & \multicolumn{1}{c|}{$\boldsymbol{\chi}^{\mathbf{2}}$} & \multicolumn{1}{c|}{ df } & \multicolumn{1}{c|}{$\boldsymbol{\chi}^{2} / \mathbf{d f}$} & \multicolumn{1}{c|}{ RMSEA } & GFI & CFI \\
\hline $\mathrm{H} 1 \mathrm{ICT} \rightarrow \mathrm{KS}$ & 0.774 & 8.488 & 26.600 & 17 & 1.565 & 0.041 & 0.981 & 0.989 \\
\hline $\mathrm{H} 2: \mathrm{TZS} \rightarrow \mathrm{KS}$ & 0.039 & 0.833 & - & - & - & - & - & - \\
\hline $\mathrm{H} 3: \mathrm{HC} \rightarrow \mathrm{KS}$ & 0.583 & 6.283 & 21.109 & 13 & 1.624 & 0.043 & 0.982 & 0.986 \\
\hline $\mathrm{H} 4: \mathrm{CC} \rightarrow \mathrm{KS}$ & 0.698 & 7.759 & 22.916 & 13 & 1.763 & 0.048 & 0.981 & 0.984 \\
\hline $\mathrm{H} 5: \mathrm{KAS} \rightarrow \mathrm{KS}$ & 0.774 & 7.708 & 11.998 & 8 & 1.500 & 0.039 & 0.988 & 0.993 \\
\hline $\mathrm{H} 6: \mathrm{TR} \rightarrow \mathrm{KS}$ & 0.626 & 7.313 & 26.288 & 13 & 2.022 & 0.055 & 0.978 & 0.980 \\
\hline
\end{tabular}

Thirdly, unlike the hypothesis we proposed, the degree of time separation across time zones has no significant effect on knowledge sharing of team members. It may be due to the following two reasons. First of all, in the current global context, communication technologies are diverse. Team members across time zones can communicate in real time with various convenient and fast tools such as QQ, e-mail, social networking sites, Weibo, and WeChat. With the coexistence of communication methods, the time difference may not have a significant effect. Secondly, this study sample shows that $55.6 \%$ of respondents have a time lag of 0-3 hours. Most of these doctors have been to Japan, South Korea, Australia, India, or central Russia. Although these countries have time difference with 
Table 7. Hypothesis Test

\begin{tabular}{|l|l|}
\hline \multicolumn{1}{|c|}{ Hypothesis } & \multicolumn{1}{c|}{ results } \\
\hline H1: Information and Communication Technology $\rightarrow$ Knowledge Sharing $(+)$ & support \\
\hline H2: Time separation across time zones $\rightarrow$ knowledge sharing $(-)$ & reject \\
\hline H3: Hospital culture characteristics $\rightarrow$ knowledge sharing $(+)$ & support \\
\hline H4: Intercultural Communication Capability $\rightarrow$ Knowledge Sharing $(+)$ & support \\
\hline H5: Medical Knowledge Skills $\rightarrow$ Knowledge Sharing $(+)$ & support \\
\hline H6: Trust $\rightarrow$ Knowledge Sharing $(+)$ & support \\
\hline
\end{tabular}

China, it is not obvious that there is still a large part of time overlap among medical team members. Communication may not be obviously hindered in the context of information technology development.

\section{RESEARCH CONCLUSIONS AND IMPLICATIONS}

\subsection{Research Conclusion}

The implications of our research are far-reaching. Multinational corporations refer to organizations operating in many regions and employing talents from transnational and cross-cultural backgrounds (Kumar et al, 2019). The 24HrKF-based e-health service operation is a paradigm for the global operation of e-health and is an extension of $24 \mathrm{HrKF}$ application in the medical field. Through this mode of operation, decentralized medical teams around the world can establish effective cooperation and provide timely, scientific and high-quality medical services to improve the capability of medical collaborative innovation.

Many studies have explored how transnational corporations organize internal resources to overcome various distance dimensions in the process of ensuring knowledge transfer (Bates, Heitmueller \& Saria, 2018). This paper focuses on the hot issues of collaborative electronic medical innovation in hospitals and combines $24 \mathrm{HrKF}$ operation mode with all-day operation. First of all, it reviews and summarizes the research results of 24HrKF's operation, hospital knowledge sharing, and factors affecting the knowledge sharing of multinational electronic medical teams at home and abroad. Secondly, based on the influencing factors of knowledge sharing among multinational electronic medical teams, this research is combined with characteristics of $24 \mathrm{HrKF}$ distributed e-health teams and establishes an essential factors model of knowledge sharing, and 338 questionnaires from multinational medical team members are used to verify the impact of the key factors on medical team knowledge sharing.

Based on the knowledge sharing factors of the $24 \mathrm{HrKF}$ transnational electronic medical teams, the research combines $24 \mathrm{HrKF}$ ideas with distributed team characteristics and verifies the information, communication technologies, hospital cultural characteristics, cross-cultural communication, medical knowledge skills, trust and any other factors from the perspective of doctors' cognition and collaboration. This research finds that in the collaborative context of transnational electronic medical team based on 24HrKF, the use of Information and Communication Technology (ICT) (Zelmer et al., 2017; Scott et al., 2018; Bardhan Krishnan \& Lin, 2013; Mitchell, 2003; Tallman \& Chacar, 2011; Griffith \& Neale, 2003), cross-cultural communication skills (CC) (Marlow et al., 2018; Lauring \& Zhang, 2018; Dawes \& Gharawi, 2018), trust (TR) (Wang \& Peng, 2012; Trainer \& Redmiles, 2018; Schiuma et al., 2012), and knowledge skills (KAS) (Wang, 2004; Sutcliffe, 2002; Jehn \& Neale, 1999) have positive impacts on medical knowledge sharing. However, unlike our hypothesis, the degree of time-span separation across time zones has no significant effect on the knowledge sharing among team members. It may be caused by the following two reasons. First of all, in the current global context, 
communication technologies are rich and varied. Team members across time zones can communicate in real time through various convenient tools such as QQ, e-mail, social networking sites, WeiBo, and WeChat. With the coexistence of communication methods, the time difference may not have a significant effect. Secondly, this study sample shows that $55.6 \%$ of the respondents have a time lag of 0-3 hours. Most of these doctors have been to Japan, South Korea, Australia, India, or central Russia. Although these countries have time difference with China, the differences are not obvious. There is a large overlap in the working hours among the medical team members. In the premise of information technology development, communication may not be significantly hindered.

\subsection{Theoretical Implications}

The existing literature fragments the factors that affect knowledge sharing among transnational teams from the dimensions of organizational culture, geographical distribution, trust, and the external environment of the enterprise(Körner et al., 2016; Cummings, 2007; Sklavounos, Rotsios, \& Hajidimitriou, 2015; Jamshed \& Majeed, 2019), these studies provide direction for us to study the knowledge sharing of multinational medical teams. However, there is a lack of systematic thinking from the perspective of global resource allocation to study medical knowledge sharing among patients and medical teams. And studies have explored medical knowledge sharing among medical team members (Bordoloi \& Islam, 2012; Olivero et al., 2019; Lin, Casteel, Shigekawa, Weyrich, Roby, \& McMenamin, 2019; Avanesova \& Shamliyan, 2019), but they haven't analyzed the influence mechanism of medical knowledge sharing among multinational medical teams in the context of globalization, asynchronous, cross-time and distributed. On this basis, this paper combines the existing research results with the characteristics of $24 \mathrm{HrKF}$ distributed team, establishes a key factor model of knowledge sharing of 24HrKF electronic medical team, and expands the application scope of Cognitive Resource Diversity theory and Synergy theory. It is of theoretical significance to solve the problem of all-day, cross-time, cross-regional medical collaboration and distributed knowledge sharing among patients and medical teams in the context of global resource allocation.

\subsection{Management Implications}

First of all, for a transnational e-health team, to establish a high-efficiency global operation team, we must first create suitable atmosphere of cooperation culture and mutual trust, foster crosscultural communication among domestic doctors on the premise of ensuring the improvement of the information technology infrastructure. Identify the roles of each member of the team and ensure good collaboration of roles and responsibilities according to members' professional experience, knowledge, skills and educational background.

Secondly, in the treatment of the entire disease, the only way to eliminate the grudge is to maintain the relationship among the members of the e-health team and establish trust through communication. Although communication technology is helpful to this, face-to-face actual conversations cannot be replaced. For example, teams scattered around the country should be able to conduct actual meetings at least once a year, which will greatly facilitate communication.

Finally, the multinational e-health teams should pay full attention to the value of technical collaboration, use related collaborative technologies to help teams form their own workflow and to ensure smooth communication. With the continuous expansion of the scale of the mobile Internet and social media, we can use them to construct the optimum task organization process and apply the globally unified communication system to provide instant messaging, audio communication platform and work business approval process platform.

\section{RESEARCH LIMITATIONS AND OUTLOOK}

This study is based on the idea of 24-hour knowledge factory to study the influencing factors of knowledge sharing among transnational electronic medical teams. We only discuss some of these 
problems, which have certain limitations. Firstly, only those Chinese members of medical teams with overseas studies, foreign exchanges or foreign medical cooperation projects are selected as the research objects. No foreign team members are investigated. Secondly, in the study of influencing factors of knowledge sharing in transnational electronic medical teams, only the direct impact of variables on knowledge sharing is considered, and the influence of control variables is not analyzed, nor the mediating variables or moderating variables. In the future, we can do further analysis on the basis of our key factors model. Thirdly, whether there are differences in the mechanism of knowledge sharing in different environments, for instance, trust in different culture may has different impacts on knowledge sharing among members of 24HrKF-based e-medical teams. Future research can be carried out from the following aspects: First, follow-up research can design an English version of questionnaire and analyze of knowledge sharing among foreign members, and make a comparative analysis. Secondly, the moderating or mediating effects of various factors can be analyzed in depth, and the influence of different factors in different cultures on knowledge sharing can be considered. Thirdly, in different environment, the influence mechanism of each factor on knowledge sharing among members of $24 \mathrm{HrKF}$ electronic medical team may be different. Fourthly, the success of $24 \mathrm{HrKF}$ operations by software companies such as Lenovo and Neusoft provides an example for the application of the electronic medical industry. However, what are the key factors? Can it be copied directly to the electronic medical industry? Therefore, future research should also be based on an in-depth investigation of the key factors of the software company's $24 \mathrm{HrKF}$ operation and make further analysis of the differences in the medical industry. Fifthly, the results of this study will provide important guidance and reference for the follow-up exploration on the $24 \mathrm{HrKF}$ transnational electronic medical service model.

\section{ACKNOWLEDGMENT}

This research has been supported by the National Natural Science Foundation of China: (NSFC,71871172), Model of Risk knowledge acquisition and Platform governance in FinTech based on deep learning; (NSFC,71571139), Outlier Analytics and Model of Outlier Knowledge Management in the context of Big Data. We deeply appreciate the suggestions from fellow members of Xia's project team and Research center of Enterprise Decision Support, Key Research Institute of Humanities and Social Sciences in Universities of Hubei Province (DSS20200700). 


\section{REFERENCES}

Ahmad, F., \& Barner-Rasmussen, W. (2019). False foe? When and how code switching practices can support knowledge sharing in multinational corporations. Journal of International Management, 25(3), 100671. doi:10.1016/j.intman.2019.03.002

Alsharo, M., Gregg, D., \& Ramirez, R. (2016). Virtual team effectiveness: The role of knowledge sharing and trust. Information \& Management.

Al-Ansari, M. A., \& Alshare, K. (2019). The Impact of Technostress Components on the Employees Satisfaction and Perceived Performance. Journal of Global Information Management, 27(3), 65-86. doi:10.4018/ JGIM.2019070104

Ambos, B., \& Ambos, T. (2007). Organizing for discontinuous knowledge flows: A new perspective on the management of knowledge and innovation in MNCs. In A new generation in international strategic management (pp. 142-161). Cheltenham, UK: Edward Elgar.

Ambos, T. C., \& Ambos, B. (2009). The impact of distance on knowledge transfer effectiveness in multinational corporations. Journal of International Management, 15(1), 1-14. doi:10.1016/j.intman.2008.02.002

Kumar, M. A., Vimala, R., \& Britto, K. A. (2019). A cognitive technology based healthcare monitoring system and medical data transmission. Measurement, 146, 322-332.

Avanesova, A. A., \& Shamliyan, T. A. (2019). Worldwide implementation of telemedicine programs in association with research performance and health policy. Health Policy and Technology, 8(2), 179-191. doi:10.1016/j. hlpt.2019.04.001

Bao, J., Ke, Z. P., \& Wei, G. (2014). Research on community medical health management model based on Internet. Journal of Medical Informatics, 35(1), 7-11.

Bardhan, I., Krishnan, V. V., \& Lin, S. (2013). Team dispersion, information technology, and project performance. Production and Operations Management, 22(6), 1478-1493. doi:10.1111/j.1937-5956.2012.01366.x

Bates, D. W., Heitmueller, A., Kakad, M., \& Saria, S. (2018). Why policymakers should care about "big data" in healthcare. Health Policy and Technology, 7(2), 211-216.

Bell, G. G., \& Zaheer, A. (2007). Geography, networks, and knowledge flow. Organization Science, 18(6), 955-972. doi:10.1287/orsc. 1070.0308

Bi, J. X., Huang, P. L., \& Li, J. Q. (2012) Exploration of Collaborative Service Model in Universities Based on Collaborative Theory: A Case Study of Southeast University. Science and Technology in Chinese Universities, (4), 14-15.

Bordoloi, P., \& Islam, N. (2012). Knowledge Management Practices and Healthcare Delivery, A Contingency Framework. Electronic Journal of Knowledge Management, 10(2), 110-120.

Calvillo-Arbizu, J., Roa-Romero, L. M., Estudillo-Valderrama, M. A., Salgueira-Lazo, M., Aresté Fosalba, N., del-Castillo-Rodríguez, N. L., \& Román-Martínez, I. (2019). User-centred design for developing e-Health system for renal patients at home (AppNephro). International Journal of Medical Informatics, 125, 47-54. doi:10.1016/j.jimedinf.2019.02.007 PMID:30914180

Chan, J., \& Ghose, A. (2014). Internet's Dirty Secret: Assessing the Impact of Online Intermediaries on HIV Transmission. Management Information Systems Quarterly, 38(4), 955-976. doi:10.25300/MISQ/2014/38.4.01

Chan, K. (2014). Multiple project team membership and performance: Empirical evidence from engineering project teams. SAJEMS, 17(Special Issue), 76-90. doi:10.4102/sajems.v17i1.875

Cummings, J. N., \& Pickering, E. C. K. (2009). Flexible and distributed information systems development crossing spatial and temporal boundaries in globally distributed projects: A relational model of coordination delay. Information Systems Research, 20(3), 420-439. doi:10.1287/isre.1090.0239

Cummings, M. B. O. N. (2007). The spatial, temporal, and configurational characteristics of geographic dispersion in teams. Management Information Systems Quarterly, 31(3), 433-452. doi:10.2307/25148802 
Davenport, T. H., \& Prusak, L. (1998). Working knowledge: How organizations manage what they know. Harvard Business Press.

Dawes, S. S., \& Gharawi, M. A. (2018). Transnational public sector knowledge networks: A comparative study of contextual distances. Government Information Quarterly, 35(2), 184-194. doi:10.1016/j.giq.2018.02.002

Dessì, D., Reforgiato Recupero, D., Fenu, G., \& Consoli, S. (2018). A Recommender System of Medical Reports Leveraging Cognitive Computing and Frame Semantics. Intelligent Systems Reference Library.

Espinosa, J. A., \& Carmel, E. (2010). The impact of time separation on coordination in global software teams: A conceptual foundation. Software Process Improvement and Practice, 8(4), 249-266. doi:10.1002/spip.185

Gadd, C. S., Ho, Y. X., Cala, C. M., Blakemore, D., Chen, Q., Frisse, M. E., \& Johnson, K. B. (2011). User perspectives on the usability of a regional health information exchange. Journal of the American Medical Informatics Association, 18(5), 711-716. doi:10.1136/amiajnl-2011-000281 PMID:21622933

Gao, P. F. (2018). Research on the Generation Logic and Path Optimization of Medical Association from the Synergistic Perspective. Health Economy Research, (9), 18-20.

Griffith, T. L., \& Neale, S. M. A. (2003). Virtualness and knowledge in teams: Managing the love triangle of organizations, individuals, and information technology. Management Information Systems Quarterly, 27(2), 265-287. doi: $10.2307 / 30036531$

Gupta, A., Mattarelli, E., Seshasai, S., \& Broschak, J. (2009). Use of collaborative technologies and knowledge sharing in co-located and distributed teams: Towards the 24-h knowledge factory. The Journal of Strategic Information Systems, 18(3), 147-161. doi:10.1016/j.jsis.2009.07.001

Gupta, A., Seshasai, S., Mukherjo, S., \& Ridge, O. (2007). Offshoring: The Transition from Economic Drivers toward Strategic Global Partnership and 24-Hour Knowledge Factory. Journal of Electronic Commerce in Organizations, 5(2), 1-23. doi:10.4018/jeco.2007040101

Gupta, A. K., \& Govindarajan, V. (1991). Knowledge flows and the structure of control within multinational corporations. Academy of Management Review, 16(4), 768-792. doi:10.5465/amr.1991.4279628

Hashim, K. F., \& Tan, F. B. (2015). The mediating role of trust and commitment on members' continuous knowledge sharing intention: A commitment-trust theory perspective. International Journal of Information Management, 5(2), 145-151. doi:10.1016/j.ijinfomgt.2014.11.001

Hassan, M. K., El Desouky, A. I., Elghamrawy, S. M., \& Sarhan, A. M. (2019). Big data challenges and opportunities in healthcare informatics and smart hospitals. In Security in Smart Cities: Models, Applications, and Challenges (pp. 3-26). Springer.

Hinojo-Lucena, F.-J., Aznar-Díaz, I., Cáceres-Reche, M.-P., \& Romero-Rodríguez, J.-M. (2018). Use of social networks for international collaboration among medical students. Educación Médica, 21(2), 137-141. doi:10.1016/j.edumed.2018.08.009

Irizarry, T., Dabbs, D. V., \& Curran, C. R. (2015). Patient portals and patient engagement: A state of the science review. Journal of Medical Internet Research, 17(6), e148. doi:10.2196/jmir.4255 PMID:26104044

Jamshed, S., \& Majeed, N. (2019). Relationship between team culture and team performance through lens of knowledge sharing and team emotional intelligence. Journal of Knowledge Management, 23(1), 90-109. doi:10.1108/JKM-04-2018-0265

Jehn, K. A., \& Neale, N. M. A. (1999). Why differences make a difference: A field study of diversity, conflict, and performance in workgroups. Administrative Science Quarterly, 44(4), 741-763. doi:10.2307/2667054

Körner, M., Lippenberger, C., Becker, S., Reichler, L., Muller, C., Zimmermann, L., \& Baumeister, H. et al. (2016). Knowledge integration, teamwork and performance in health care. Journal of Health Organization and Management, 30(2), 227-243. doi:10.1108/JHOM-12-2014-0217 PMID:27052623

Kuwabara, T., Yagahara, A., \& Ogasawara, K. (2018). Evaluating the adequacy of medical care systems in Hokkaido, Japan. Health Policy and Technology, 7(3), 251-264. doi:10.1016/j.hlpt.2018.07.004 
Lauring, J., \& Zhang, L. E. (2018). Knowledge Sharing Across National Cultural Boundaries and Multinational Corporations. In The Palgrave Handbook of Knowledge Management (pp. 381-407). Palgrave Macmillan. doi:10.1007/978-3-319-71434-9_16

Lee, Y.-H., Lu, T.-E., Yang, C. C., \& Chang, G. (2019). A multilevel approach on empowering leadership and safety behavior in the medical industry: The mediating effects of knowledge sharing and safety climate. Safety Science, 117, 1-9. doi:10.1016/j.ssci.2019.03.022

Leung, L., \& Chen, C. (2019). E-health/m-health adoption and lifestyle improvements: Exploring the roles of technology readiness, the expectation-confirmation model, and health-related information activities. Telecommunications Policy, 43(6), 563-575. doi:10.1016/j.telpol.2019.01.005

Lin, L. A., Casteel, D., Shigekawa, E., Weyrich, M. S., Roby, D. H., \& McMenamin, S. B. (2019). Telemedicinedelivered treatment interventions for substance use disorders: A systematic review. Journal of Substance Abuse Treatment, 101, 38-49. doi:10.1016/j.jsat.2019.03.007 PMID:31006553

Liu, Z. G., \& Lin, C. Y. (2004). Strengthen knowledge management, improve the core competitiveness of hospitals. Journal of Medical Informatics, 25(6), 411-412.

Mannix, E., \& Neale, M. A. (2005). What differences make a difference?: The promise and reality of diverse teams in organizations. Psychological Science in the Public Interest, 6(2), 31-55. doi:10.1111/j.1529-1006.2005.00022.x PMID:26158478

Marlow, S. L., Lacerenza, C. N., Paoletti, J., Burke, C. S., \& Salas, E. (2018). Does team communication represent a one-size-fits-all approach?: A meta-analysis of team communication and performance. Organizational Behavior and Human Decision Processes, 144, 145-170. doi:10.1016/j.obhdp.2017.08.001

Mitchell, H. J. (2003). Technology and Knowledge Management: Is Technology Just an Enabler or Does it also Add Value? In Knowledge management. Hershey, PA: IGI Publishing. doi:10.4018/978-1-93177-751-3.ch006

Nisha, N., Iqbal, M., \& Rifat, A. (2019). The Changing Paradigm of Health and Mobile Phones. Journal of Global Information Management, 27(1), 19-46. doi:10.4018/JGIM.2019010102

Olivero, E., Bert, F., Thomas, R., Scarmozzino, A., Raciti, I. M., Gualano, M. R., \& Siliquini, R. (2019). E-tools for hospital management: An overview of smartphone applications for health professionals. International Journal of Medical Informatics, 124, 58-67. doi:10.1016/j.ijmedinf.2019.01.010 PMID:30784427

Olson, G. M., \& Olson, J. S. (2000). Distance matters. Human-Computer Interaction, 15(2-3), 139-178. doi:10.1207/S15327051HCI1523_4

Oyemomi, O., Liu, S., Neaga, I., Chen, H., \& Nakpodia, F. (2018). How cultural impact on knowledge sharing contributes to organizational performance: Using the FSQCA approach. Journal of Business Research, 94, 313-319.

Piening, E. P., Salge, T. O., \& Schäfer, S. (2016). Innovating across boundaries: A portfolio perspective on innovation partnerships of multinational corporations. Journal of World Business, 51(3), 474-485. doi:10.1016/j. jwb.2016.01.001

Razmak, J., Bélanger, C. H., \& Farhan, W. (2018). Development of a techno-humanist model for e-health adoption of innovative technology. International Journal of Medical Informatics, 174, 22-35. PMID:30409347

Schiuma, G., Franssila, H., Okkonen, J., Savolainen, R., \& Talja, S. (2012). The formation of coordinative knowledge practices in distributed work: Towards an explanatory model. Journal of Knowledge Management, 16(4), 650-665. doi:10.1108/13673271211246202

Scott, C. K., Karem, P., Shifflett, K., Vegi, L., Ravi, K., \& Brooks, M. (2018). Evaluating barriers to adopting telemedicine worldwide: A systematic review. Journal of Telemedicine and Telecare, 24(1), 4-12. doi:10.1177/1357633X16674087 PMID:29320966

Shaw, B., \& Luiz, J. M. (2017). The Impact of Distance (External) and Organizational Factors (Internal) on the Knowledge Chain of Multinational Corporations: South Africa as a Host Country. Thunderbird International Business Review.

Singer, D. R., Bakker, L., \& Redekop, K. (2019). European Cooperation on Healthcare. Health Policy and Technology, 8(1), 1-2. doi:10.1016/j.hlpt.2019.03.001 
Sklavounos, N. S., Rotsios, K. P., \& Hajidimitriou, Y. A. (2015). Trust in isas: The role of foreign partners' knowledge transfer, senior management commitment, goal congruity and control. Procedia Economics and Finance, 33, 331-339. doi:10.1016/S2212-5671(15)01717-7

Srivastava, S. C., \& Shainesh, G. (2015). Bridging the service divide through digitally enabled service innovations: evidence from Indian healthcare service providers. Society for Information Management and The Management Information Systems Research Center.

Staadt, J. (2015). The cultural analysis of soft systems methodology and the configuration model of organizational culture. SAGE Open, 5(2).

Sutcliffe, B. K. M. (2002). Comparing alternative conceptualizations of functional diversity in management teams: Process and performance effects. Academy of Management Journal, 45(5), 875-893.

Su, J., He, B., Guan, Y., Jiang, J., \& Yang, J. (2017). Developing a cardiovascular disease risk factor annotated corpus of Chinese electronic medical records. BMC Medical Informatics and Decision Making, 17(1), 117. doi:10.1186/s12911-017-0512-7 PMID:28789686

Tagliaventi, M. R., \& Mattarelli, E. (2006). The role of networks of practice, value sharing, and operational proximity in knowledge flows between professional groups. Human Relations, 59(3), 291-319. doi:10.1177/0018726706064175

Tallman, S. \& Chacar, A. S. (2011). Knowledge accumulation and dissemination in mnes: a practice-based framework. Journal of Management Studies, 48(2).

Trainer, E. H., \& Redmiles, D. F. (2018). Bridging the gap between awareness and trust in globally distributed software teams. Journal of Systems and Software, 144, 328-341. doi:10.1016/j.jss.2018.06.028

Tsuruya, N., Kawashima, T., Shiozuka, M., Nakanishi, Y., \& Sugiyama, D. (2018). Academia-industry Cooperation in the Medical Field: Matching Opportunities in Japan. Clinical Therapeutics, 40(11), 1807-1812. doi:10.1016/j.clinthera.2018.10.010 PMID:30415863

Wang, H. (2004). Communication is the key to the success of project management. Business Economics, (6), 91-92.

Wang, Y., \& Peng, C. (2012). Research on the relationship between knowledge heterogeneity and knowledge innovation performance. Science and Technology Progress and Policy, 29(4), 119-123.

Wickramasinghe, N., Chalasani, S., Goldberg, S., \& Koritala, S. (2012). The benefits of wireless enabled applications to facilitate superior healthcare delivery: The case of diamond. International Journal of E-Health and Medical Communications, 3(4), 15-30. doi:10.4018/jehmc.2012100102

Williams, K. Y., \& O'Reilly, C. A. (1998). Demography and diversity in organizations: A review of 40 years of research. Research in Organizational Behavior, 20, 77-140.

Xia, H. S., \& Li, F. (2016). Research on Knowledge Sharing Process Improvement Model in Large Data Context from 24HrKF Perspective. Industrial Engineering and Management, 21(5), 83-91.

Zelmer, J., Ronchi, E., Hyppönen, H., Lupiáñez-Villanueva, F., Codagnone, C., Nøhr, C., \& Adler-Milstein, J. et al. (2017). International health IT benchmarking: Learning from cross-country comparisons. Journal of the American Medical Informatics Association, 24(2), 271-379. PMID:27554825

Zhang, B. (2016). Research on the construction of knowledge sharing system based on the core competence of hospital. Tianjin University. 
Xia Huosong, a Hubei Xishui native (1964- ), graduated from Huazhong University of Science and Technology of China. Huosong Xia is a professor in the school of management of the Wuhan Textile University. He was a visiting scholar at Eller College of Management of the University of Arizona, USA from 2006 to 2007. His main research interests are: knowledge management, data mining and, e-Commerce and Logistics Information System. His publications have appeared in refereed over 100 papers in journals, book chapters \& conferences such as Journal of Knowledge Management, International Journal of Knowledge Management, Journal of Knowledge Management Practice, Knowledge Management Research \& Practice, Electronic Commerce Research, Journal of Computer Information Systems, Decision Support Systems (DSS), Information Discovery and Delivery, International Journal of Management, Journal of Systems Science and Information, Journal of Grey System, Financial Innovation (Springer). His publications have cited more than 700 citations. He has got 4 projects of research funding such as National Social Science Foundation of China and National Science Foundation of China. He may be contacted at E-mail Box: bxxhs@sina.com; 1179094639@qq.com.

Xiong Gan graduated with a doctor's degree from Wuhan University and master's degree from Wuhan Textile University. Xiong Gan is working at the Higher Education Research Institute, Wuhan Academy of Educational Science, Wuhan.

Juan Weng graduated from Wuhan Textile University. 